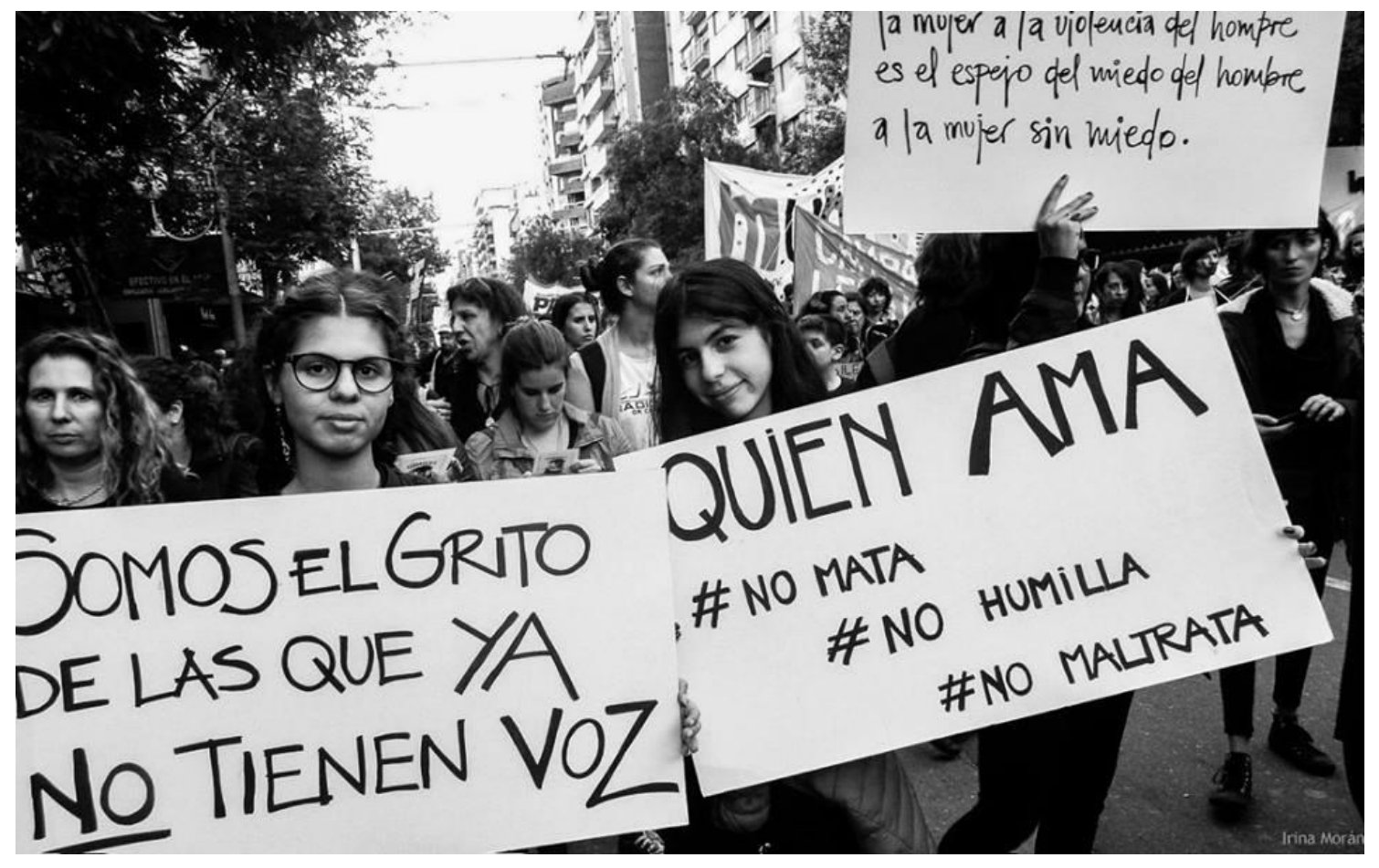




\title{
ESCOLA DE PRINCESAS: ESTRATÉGIAS FICCIONAIS E DISCURSOS ANDROCÊNTRICOS
}

\author{
Andreia Aparecida Marin ${ }^{1}$ \\ Stheffany Cruvinel Martins ${ }^{2}$
}

Resumo: A presente escrita gira em torno da naturalização de representações a respeito da mulher, veiculadas no discurso inerente ao currículo das Escolas de Princesas. A necessidade de uma reflexão sobre tais representações se justifica pela suspeita de que fazem retroceder amplas discussões críticas sobre a construção social do conceito de mulher, sua objetivação e as contenções nela fundadas. A argumentação teórica se desenvolve no sentido de demonstrar que a pedagogia das referidas escolas oculta ou ignora discussões feministas, tanto amparadas em Beauvoir quanto em Butler - duas importantes pensadoras que influenciam vertentes dos feminismos contemporâneos.

Palavras-chave: Mulher. Feminismo. Escola de Princesas. Representação. Androcentrismo.

\section{SCHOOL OF PRINCES: fictional strategies and androcentric discourses}

\begin{abstract}
This paper discusses the naturalization of representations about women conveyed in the discourse presented in the Escola de Princesas's (Princesses' School) curriculum. The need for an reflection of such representation is justified by the suspicion that these schools and their discourse set back broad critical discussions on the social constructs of the concept of being a woman, of women's objectivation, and of the restraints these concepts hold. The discussion goes on to show that the pedagogy of the aforementioned schools either conceals or ignores feminist discussions, based on both Beauvoir and Butler, two important theorists that influence contemporary feminism variants.
\end{abstract}

Key-words: Women. Feminism. Princesses' School. Representation. Androcentrism.

\section{INTRODUÇÃO}

Motivou nossa reflexão, aqui apresentada, uma inquietação que julgamos merecer tanto a atenção daqueles que trabalham com educação quanto a análise crítica de toda a sociedade. Temos acompanhado os avanços e derivações do discurso feminista na atualidade, de forma que se tornou foco de nossa atenção, traduzidas, nesta escrita, as ideias materializadas na criação recente de uma escola, que contrariam os questionamentos de diferentes vertentes do movimento feminista.

Nosso objeto é a materialização de ideias, representações e conceitos, tão tardios quanto problemáticos, a respeito do que é ser mulher em uma sociedade androcêntrica. Poderíamos estar, aqui, repetindo várias manifestações críticas de uma situação histórica que já aponta para uma desnaturalização dessas representações, ou mesmo, de seu ultrapassamento. Mas não. Nosso objeto tem nome, endereço e uma robusta imagem: as ideias materializadas na Escola de Princesas, documentadas no seu currículo e justificadas no que sua fundadora chama de Pedagogia de Princesas. Tal escola surgiu na cidade de Uberlândia, no ano de 2013, idealizada por Nathalia de

\footnotetext{
${ }^{1}$ Grad. Ciências Biológicas/USP e Filosofia/UFPR. Dra. em Ecologia e Recursos Naturais/UFSCar. Docente no Instituto de Educação, Letras, Artes e Ciências Humanas e Sociais/UFTM.

${ }^{2}$ Graduação em História pela Universidade Federal do Triângulo Mineiro.
} 
Mesquita, tendo se estendido, em regime de franquias, a várias outras cidades do Brasil, estando em franca expansão. Trata-se de uma escola cujo público-alvo é as meninas de quatro a quinze anos de idade e se propõe a oferecer serviços de excelência que propiciem experiências do dia a dia da realeza.

Nossas reflexões partem do discurso dessa suposta pedagogia, revelado nas declarações de sua idealizadora e em seu currículo, de onde são destacados elementos para pensarmos as objetivações da mulher em nosso universo conceitual e sua limitação em nossas configurações sociais, baseadas na centralidade do homem. Os elementos que focamos para esse destaque são: a ideia de uma mulher completa; discursos sobre valores morais catalisadores da contenção da mulher; vínculo da imagem da princesa com androcentrismo; associação do papel social da mulher com o espaço doméstico. Julgamos oportuno antecipar, a título de melhor qualificação da suspeita do caráter androcêntrico da proposta, o tópico curricular a partir do qual se ensinam meninas a esperarem os seus príncipes, recuperando valores da família e do matrimônio. Várias perguntas são possíveis já a partir desse primeiro contato com o currículo: para que mundo essa proposta pedagógica pretende formar tais crianças? Por que, desde o ponto de origem, restringem tal formação ao universo feminino? Que representações sobre o que é ser mulher estão por trás de preocupações como a espera do príncipe, as boas maneiras e a eficiência em administrar o lar ao mesmo tempo em que pretende garantir sucesso no espaço de trabalho?

Precisamos ter paciência em refletir sobre essas questões, depois de tantas tentativas de rupturas com o androcentrismo, provocadas no espaço contemporâneo. Elas não se esgotam em si, mas apontam para uma anterioridade que vale, sem dúvidas, questionar: por que as representações que encontraremos, ao buscarmos suas respostas, denunciam um retorno ou uma reminiscência ou, talvez, uma reverberação ingênua? Sim... Supúnhamos já estar num momento avançado do caminho de superação de uma mentalidade machista ou de uma contraposição a qualquer forma de sua manifestação. Então, deparamo-nos com uma instituição escolar revivendo, relembrando ou reverberando ideias e atitudes fundadas em uma centralidade do homem que, por práticas sutis ou diretivas, submete a mulher e obscurece sua potência existencial.

Ainda mais agravante, já pensávamos em considerar a possibilidade de um momento futuro quando seria perfeitamente dispensável falarmos em nome da suspensão das diferenças, ou, ao menos, da política da diferença, para pensarmos uma igualdade que não faria subsumir as singularidades, mas admitiria que as diferenciações 
são móveis, derivantes, na forma de um constante devir, portanto, não justificariam qualquer juízo de valor ou limitação do espaço existencial do outro. Mas, de repente, toda a imobilidade dos conceitos de homem e mulher volta a materializar-se diante de nós, com toda a perniciosa contenção que fez subsumir a potência existencial de um nos projetos imperativos de outro. Uma objetivação marcada por formas sutis ou expressas de violência, por exercícios de poder já tão denunciados na nomeação e qualificação do que é ser mulher. Tudo se passa como se a história ocidental jamais tivesse testemunhado os anúncios críticos de Simone de Beauvoir, de Judith Butler, entre tantas outras mulheres que se colocaram diante e contra qualquer forma de dominação do feminino ou de governo das diferenças.

Esperamos, ao final de nossas reflexões, ter conseguido destacar elementos suficientes para caracterizar um possível retrocesso que tal iniciativa pode significar para o amadurecimento ético atrelado ao ultrapassamento das relações baseadas em critérios de distinção, exclusão e dominação em nossa sociedade contemporânea.

\section{FICÇÕES E CONTENÇÃO SOCIAL: a ideia de mulher integral}

A capacidade humana de criação de ficções e de sustentar estratégias de regulação social já não é tema inaugural. É possível que a busca de seus primórdios nos surpreenda, que sejamos levados a pensar que foi tal capacidade que permitiu não somente a sobrevivência da espécie $H$. sapiens, como sua distribuição no planeta, em detrimento de outros viventes. Harari investiga a respeito da possibilidade da capacidade de pensar e comunicar coisas imaginárias ter dado as condições de uma configuração social complexa, baseada na cooperação que permitiria o destaque dos humanos sapientes. A competência em "convencer milhões de pessoas a acreditarem em histórias sobre deuses, nações ou empresas" teria dado a eles imenso poder, porque "possibilita que milhões de estranhos cooperem para objetivos em comum" (HARARI, 2015, p. 48).

Essa linguagem, baseada em um mundo ampliado pela ficção, está na base de muitas representações que sustentam comportamentos regulados e estratégias de contenção. Nesse sentido, o reconhecimento do imaginário e das narrativas ficcionais como fundantes da organização social parece incontornável. Poder constituir conceitos sobre viventes e referir-se a eles a partir desse conceito é já delimitar seu alcance existencial.

Podemos já, dentro do campo de reflexões que sustenta algumas vertentes feministas, fazer valer as considerações de Butler a respeito de uma relação de 
alteridade sempre baseada em uma distinção entre o eu e o outro, que acaba por fundamentar mecanismos de dominação. Para a autora, " a linguagem da apropriação “pertence a uma estratégia de dominação que joga o 'eu' contra o 'Outro', e, uma vez efetuada a separação, cria um conjunto artificial de questões sobre a possibilidade de conhecer e resgatar o Outro" (BUTLER, 2003, p. 208). Pela mediação intelectual e pela linguagem, com ela interpenetrada, o humano julgou ter se destacado dos outros animais e constituiu formas distintas de fortalecimento da própria espécie, incluindo o controle comportamental, por meio de adesão a padrões sociais sustentados, quase sempre, pelo binarismo Eu-Outro.

De outra perspectiva do movimento feminista, destacamos a provocação de Beauvoir sobre a alteridade. A pensadora considera que naturalizamos a ideia de que a existência do Outro é sempre uma ameaça, um perigo. O drama da relação com o Outro deriva de uma forma de pensar a alteridade sempre a partir de uma negação. O outro é sempre um outro radical, colocado desde o princípio em oposição. É justamente esse mal, essa consistência dramática, que Beauvoir denuncia na forma de conceituação do que é ser mulher:

Ora, o que define de maneira singular a situação da mulher é que, sendo, como todo ser humano, uma liberdade autônoma, descobre-se e escolhe-se num mundo em que os homens lhe impõem a condição do Outro. Pretende-se torná-la objeto, voltá-la à imanência, porquanto sua transcendência será perpetuamente transcendida por outra consciência essencial e soberana. (BEAUVOIR, 1970, p. 23).

Consideremos: o humano constituiu várias ficções sobre sua própria natureza. Na maioria delas, a plena humanidade depende de uma suspensão da animalidade, o que justifica seus esforços em conter qualquer instinto ou comportamento não mediado pelas características que o definem: razão; linguagem; capacidade de modular emoções; consciência da morte.

A consequência primeira dessa objetivação é a naturalização da ideia segundo a qual se pode prever e alcançar algo como a essência do humano, reconhecendo, a partir daí, seu ser integral. O ser humano não só julgou poder dizer o que são as coisas e nomear os outros viventes, mas lançou-se a uma busca de definição de um si mesmo, desdobrando dessa tarefa, a construção de um projeto existencial, por vias morais e pedagógicas, que permitisse o desenvolvimento da totalidade de seu próprio ser. Não são poucos os discursos que reverberam a ficção do ser humano integral, incluindo, paradoxalmente, aqueles que se formaram a partir da crítica à separação entre sujeito e 
objeto e à centralidade da razão. O paradoxal está, justamente, em se negar a objetivação do ser enquanto se busca, pela intelecção, o desvelamento e o posterior desenvolvimento daquelas dimensões não racionais que constituem o humano. Fazem parte de pedagogias contemporâneas a aposta na possibilidade de desenvolvimento do ser humano integral, em suas dimensões sensíveis, racionais, espirituais etc. $\mathrm{Na}$ mesma esteira, faz parte do discurso das Escolas de Princesas, a proposta de garantir a formação da mulher integral, conforme informa a idealizadora: "eu queria um novo conceito de princesa, uma mulher completa, que domina tanto o gerenciamento da casa quanto a realização profissional” (MESQUITA apud PAULINO, 2013).

De todas essas apostas de totalização, resulta, ao mesmo tempo, o testemunho de uma proposta ingênua, e do incontornável ponto cego da consciência, e o resquício de uma insistência em impor a política representacional. Permanece, não obstante, a questão incontornável - o que é ser mulher ou, ainda mais, ser uma mulher completa?, fazendo subsumir a questão coerente: quais os conceitos forjados sobre o que é ser mulher sustentam uma política representacional reguladora?

Outra consequência da objetivação é a naturalização de um limite dentro do qual cabem pequenas diferenciações compatíveis com o conceito constituído. Esse limite não é pensado a posteriori à conceituação, mas está previsto nela, anunciando-se na representação que, por fazer parte de um discurso corrente, ganha legitimidade e encaminha à adesão, em uma forma sutil de submissão. Conseguimos detectar essa condição a partir de uma atenção crítica aos discursos objetivantes. Temos sido, atualmente, receptíveis à denúncia das restrições impostas por esse modelo limitante, mas raramente levados a romper com a prática objetivante. Em outros termos, reivindicam-se a ampliação desses limites, mas não sua desnaturalização. Butler aponta para prejuízos importantes dessa condição.

A teoria feminista tem pensado que existe uma identidade, definida, compreendida pela categoria de mulheres, que não só deflagra os interesses e objetivos feministas no interior de seu próprio discurso, mas constitui o sujeito mesmo em nome de que a representação política é almejada (BUTLER, 2003, p.16).

Butler (2003) destaca que política e representação são termos polêmicos, antes de encaminhar que, se a representação serve como um termo que garante visibilidade às mulheres como sujeitos políticos, também é uma função normativa da linguagem que reforça "o que é tido como verdadeiro sobre a categoria de mulheres" (BUTLER, 2003, 
p. 16). Vale lembrar a referência que a autora faz sobre o título da obra de D. Riley, ao tratar da impossibilidade de o termo mulher denotar uma identidade: "Sou eu esse nome?" (BUTLER, 2003, p.20)

\section{OBJETIVAÇÃO E CONTENÇÃO DA POTÊNCIA EXISTENCIAL FEMININA}

Nossa tentativa, com a condução reflexiva até aqui, é colocar em pauta tanto a ideia de que se pode conhecer algo como uma mulher completa como a idealizada nas Escolas de Princesas e, sobretudo, o ocultamento do caráter regulador de qualquer discurso que se proponha a formá-la em sua integralidade, ocultando as potências existenciais femininas. Portanto, estão em questão os fundamentos da Pedagogia de Princesas.

Esses dois elementos em foco foram problematizados em diferentes momentos da constituição do discurso feminista, o que demonstra um afastamento intencional da proposta da Escola de Princesas dessas análises da superação da contenção da mulher. Destacaremos, aqui, as provocações de (Beauvoir,1970; Butler, 2003): as da primeira, acusando que ninguém nasce mulher, sendo o termo associado a uma construção social que determina, segundo interesses androcêntricos, aquilo que ela deve ser; as da segunda, opondo-se à Beauvoir, apontando a necessidade de suspender a representação de mulher em oposição à de homem, evitando um discurso baseado no binarismo EuOutro - que reforça políticas de regulação.

Beauvoir (1970), em O segundo sexo, apresenta uma análise em que denuncia o destino dado à mulher ao ser biológico e o amplo espaço garantido aos projetos existenciais masculinos. Embora essa ligação da mulher à natureza e do homem à cultura seja alvo de críticas feministas recentes que apontam aí alguma radicalização e o risco de reforçar uma suposta dualidade que, para além das diferenças inquestionáveis entre homens e mulheres, serviria como justificação para limitar os papéis femininos na vida e na sociedade. A despeito dessa crítica, evidencia-se, diante de discursos como os da Pedagogia das Princesas, que várias provocações de Beauvoir permanecem pertinentes em nossos dias.

Importante destacar a reflexão beauvoireana que distingue uma preferência da humanidade por razões de viver, em detrimento da vida, que "perante a mulher o homem se pôs como senhor; o projeto do homem não é repetir-se no tempo, é reinar sobre o instante e construir o futuro" (BEAUVOIR, 1970, p. 86). O homem, nesse sentido, está consagrado aos projetos existenciais, ao exterior, enquanto a mulher está 
destinada à vida no interior da casa, ao cuidado com a manutenção da vida.

Assim, o paternalismo, que reclama a mulher no lar, define-a como sentimento, interioridade e imanência; na realidade, todo existente é, ao mesmo tempo, imanência e transcendência; quando não lhe propõem um objetivo, quando o impedem de atingir algum, quando o frustram em sua vitória, sua transcendência cai inutilmente no passado, isto é, recai na imanência (BEAUVOIR, 1970, p. 301).

Ao nos depararmos com uma pedagogia que, a partir da proposta de formação da mulher integral, sugere a preparação de meninas e adolescentes para as habilidades domésticas e de cuidado familiar, somos forçados a admitir a pertinência e a atualidade dessa reflexão. Na Escola de Princesas, o currículo é direcionado para o detalhamento do que pretendem como uma mulher completa, toda dimensionada na imagem das princesas de narrativas ficcionais, iniciando justamente pelo tópico identidade de princesa, enfatizando seu caráter, princípios morais, seu destino espelhado em princesas reais e fictícias. Vencida essa parte introdutória, são enfocados os modelos de relacionamentos da princesa, os cuidados estéticos, a etiqueta social e a organização e limpeza do "castelo".

Na mesma esteira desse reducionismo, destacamos a Escola de Assunción, apresentada por Paternostro (1999, p. 302), em que as garotas, para se formarem, precisam "apresentar não uma tese final, mas uma 'canastilla de bebé', um enxoval completo para uma criança que vai nascer", sendo que tanto os pais quanto as alunas "achavam que este era um projeto e um trabalho digno de mérito".

Destaquemos, da proposta da Escola de Princesas, a preocupação com a questão da estética. Segundo Beauvoir (2003, p. 202), "o homem deseja que a mulher seja, ao mesmo tempo, animal e planta, e que se esconda por trás de uma armadura fabricada". É nesse sentido que é atraído por adornos e por um padrão estético próprio da cultura do seu tempo: "na mulher enfeitada, a Natureza está presente, mas cativa, moldada por uma vontade humana segundo o desejo do homem. Uma mulher é tanto mais desejável quanto mais se acha nela desabrochada e escravizada a Natureza" (BEAUVOIR, 1970, p. 201).

As características desejadas pela idealizadora da Escola de Princesas estão colocadas, direta ou indiretamente, na direção de predicados que reforçam interesses androcêntricos: uma mulher educada com os valores da família e do matrimônio, que 
espera seu príncipe ${ }^{3}$ e que "domina tanto o gerenciamento da casa quanto a realização profissional” (MESQUITA apud PAULINO, 2013.) Toda linguagem que funda seu discurso reflete uma "mulher para", com um destino já dado, capturada desde o princípio pelo encantamento de uma ficção que constitui um mundo cujas relações entre o homens e mulheres tendem ao equilíbrio, enquanto a vida fática mostra diferenciações intermináveis dessas relações, quase sempre não harmoniosas. Tal linguagem reforça, nesse sentido, um papel regulador que destina a mulher a um lugar onde o sucesso está vinculado ao êxito no relacionamento com um príncipe.

Sob o ponto de vista das análises de Butler, também podemos identificar problemas importantes nesse modelo de formação. Todo discurso das Escolas de Princesas está pautado em um único modelo constituído sobre mulher. Ocorre que, como apontado por Butler (2003, p. 16), o próprio sujeito das mulheres não pode ser compreendido em termos estáveis ou permanentes. Assim, ela condena a permanência da identidade (mulher, negra, branca, lésbica) como matriz natural de unidade e defende pontos de coalizão conscientes de afinidade e parentesco político. Também, para Haraway (1994, p. 250), não há absolutamente nada a respeito do ser "mulher" que aglutine naturalmente todas as mulheres, sendo impossível fornecer a base para a crença em uma unidade essencial para a categoria gênero, assim como para raça e classe.

É necessário considerar que, se o discurso se funda em um modelo unívoco de formação da mulher, baseado nas características das princesas reais e fictícias, ele já foi legitimado e consolidado na sociedade, sem o que não se poderia prever a admissão e o sucesso da proposta. Nos termos de Butler (2003, p.16), os domínios da representação estabeleceram as condições de formação dos sujeitos, de forma que tal representação só possa fazer referência a algo já reconhecido como sujeito. Nas ficções fundacionistas, que sustentam as propostas da Pedagogia de Princesas, o sujeito mulher já está dado de antemão, sem qualquer possibilidade de dúvida, motivo pelo qual pode lhe ser indicado um destino sem contorno. Pela força de seus elementos imaginários, a adesão da sociedade, incluindo de mães de meninas submetidas a esse destino, é motivada por representações androcêntricas, historicamente naturalizadas.

A título de oportunidade, julgamos importante destacar que a força das ficções que sustenta os discursos androcêntricos nas escolas de princesas pode tornar-se um problema no interior dos próprios movimentos feministas. Butler (2003) discute esse

${ }^{3}$ Disponível em: www.escoladeprincesas.net. 
risco, apontando que tais ficções acabam por reivindicar um sujeito, uma identidade feminina, a ser colocado na pauta dos discursos de emancipação. Cita, nesse sentido, o pensamento de Irigary, segundo o qual, “o feminismo jamais poderá ser a marca de um sujeito, como sugere Beauvoir". Continua: “esse modo falocêntrico de significar o sexo feminino reproduz perpetuamente as fantasias de seu próprio desejo autoengrandecedor" (BUTLER, 2003, p.30). Podemos considerar a problemática do empoderamento, que se sustenta nesse padrão dual.

\section{REAÇÕES RADICAIS E OUTROS MODOS DE OBJETIVAÇÃO}

Julgamos que a evidente distinção entre os pensamentos de Beauvoir e Butler não destitui de importância um ou outro, uma vez que entendemos que há reverberações na sociedade atual de formas distintas de contenção da mulher, a exemplo do que ocorre no discurso da Pedagogia de Princesas, que pode ser colocadas sob a luz de ambas as análises críticas. No entanto, para darmos continuidade, nesse momento, às reflexões sobre as reações a esse discurso, optamos por enfatizar algumas questões adicionais colocadas por Butler (2003, p.31): “para Beauvoir, o 'sujeito', na analítica existencial de misoginia, é sempre já masculino [...] diferenciando-se de um 'Outro' feminino que está fora das normas universalizantes que constituem a condição de pessoa, inexoravelmente 'particular', corporificado e condenado à imanência'.

Podemos nos perguntar se essa distinção Eu-Outro não reforça o mesmo princípio de exclusão que, historicamente, justificou a destinação da mulher. Algo como uma herança epistemológica dos discursos de objetivação reforça esse binarismo como uma estratégia que “estabelece o 'eu’ na e através da oposição, o que reifica essa oposição como uma necessidade, ocultando o aparato discursivo pelo qual o próprio binário é constituído" (BUTLER, 2003, p.208). No binômio homem-mulher, as representações que fundamentam a distinção não são justificadas a cada vez que se discursa sobre a singularidade ou supremacia de um por oposição ao outro. Nesse sentido, destacamos outra contribuição da autora, quando aponta para uma superação dessa lógica: "a crítica feminista tem de explorar as afirmações totalizantes da economia significante masculina, mas também deve permanecer autocrítica em relação aos gestos totalizantes do feminino" (BUTLER, 2003, p. 33).

Há, dessa forma, um problema que se coloca ao discurso de empoderamento da mulher. Se o objetivo é abrir espaços de exercício de poder de um sujeito próprio do feminino, certamente está subentendido um Outro, a quem toda forma de resistência se 
coloca. Propor um movimento dessa natureza, contornando o aparato discursivo binário, é tarefa que exige a quebra de várias representações cristalizadas e de políticas representacionais.

Nesse contexto reflexivo, apresentamos algumas experiências de reação ao discurso cristalizado no currículo das Escolas de Princesas, entre as quais, a proposta de desprincesamento em diferentes contextos. Consideramos que essas iniciativas se justificam pela necessidade de manifestação contra as formas gritantes de contenção, que já se pensava estarem em superação. No entanto, ao que parece, não apenas o padrão binário se repete no interior dessas discursividades, mas também o anúncio de características que definiriam outros tipos de mulher, o que significa o não contorno da ideia de sujeito feminino e de uma política legitimada nessa representação.

No texto Cursos de "desprincesamento": estratégias feministas de resistência, as autoras Smyl e Santos (2017) citam a experiência de uma escola em Iquique, no norte do Chile, onde foi criada, vinculada ao movimento de Proteção de Direitos da Infância, uma oficina destinada a meninas entre 9 e 15 anos, com o objetivo de discutir temas como amor romântico e autonomia feminina, além de oportunizar a reflexão sobre o que é ser mulher, questionando os estereótipos criados pelos filmes de princesas. As atividades propostas consistiam em debates, aulas de defesa pessoal, atividades manuais e aulas de canto (SMYL; SANTOS, 2017, p. 7). Segundo as autoras, as experiências inspiradas em Iquique apontam para a construção de um "feminismo de resistência à dominação", um movimento "que interseccione as múltiplas opressões, sejam elas de raça, de classe, sejam de gênero, que representem essas mulheres e sejam um contraponto de resistência a opressões múltiplas" (SMYL; SANTOS, 2017, p. 8). Acrescentam que experiências com intuitos semelhantes têm sido desenvolvidas em algumas cidades brasileiras, cujas ações incluem workshops, cursos, oficinas adaptadas às necessidades locais, reconhecidas como "lições de desprincesamento".

Cabem algumas reflexões. Não ousaremos negar a importância de tais iniciativas que dão visibilidade à problemática proposta das Escolas de Princesas, do ponto de vista da justificativa do discurso feminista de resistência. No entanto, talvez seja válido nos perguntarmos até que ponto essas iniciativas não repetem a constituição de conceitos de mulher, reforçando características contrárias às almejadas pelas Escolas de Princesas, contrariando, paradoxalmente, seu próprio objetivo inicial, o de questionar estereótipos. A pergunta que serve como ponto de partida da proposta - O 
que é ser mulher? - já não revela o pressuposto de que se trata de uma pergunta possível? Em outros termos, não prevê que, negando a mulher princesa, poderá chegar a uma outra subjetividade feminina que passa a significar algo como um modelo de mulher desprincesada?

Essas perguntas não podem ser ignoradas, ainda que a apresentação do projeto contemple, como em um dos exemplos dos cursos dados, a ideia de que "meninas e mulheres precisam ser livres para ser o que quiserem ser" (SMYL; SANTOS, 2017, p. 8). Mesmo porque as autoras citam, na sequência dessa apresentação, alguns temas tratados nos cursos, entre os quais destacamos o tema da rainha, elaborado para se trabalhar a autoestima e o empoderamento das meninas, desconstruindo estereótipos de beleza. O título escolhido pelas proponentes da temática comporta a seguinte assertiva: “Toda menina é uma rainha! - Meninas são Rainhas? Sim!?. Várias preocupações podem ser destacadas dessa assertiva: o pressuposto de uma identidade feminina; a ligação dessa identidade com a imagem de rainhas, que merece uma vasta reflexão que evidencie as representações sobre a mulher por traz do termo; a ideia de que qualquer padrão de beleza deva ser reconhecido, mas desde seu enquadramento nessas representações associadas ao termo rainha; por fim, a ideia de que esse reconhecimento e autopositivação, segundo tal identidade, possam significar, pragmaticamente, a ampliação do espaço de liberdade dessas meninas e o seu empoderamento. Reconhecerse como rainha, não mais como a princesa do conto de fadas, pode conduzir a qual liberdade?

Para além dessas preocupações, devemos destacar a questão sobre a condução da infância a um destino previamente vislumbrado, tanto nas Escolas de Princesas como nas ações de desprincesamento. Há, ao que parece, o resquício de uma ideia de infância como incompletude, como algo a ser conduzido à integralidade do ser adulto, carecendo de um projeto que garanta a formação de características humanas previamente pensadas e, nesse caso, perfeitamente comprometidas com o binarismo feminino-masculino. A imagem da mulher insinuada como meta dessas ações já não é mais a princesa, mas não deixa de revelar um modelo de mulher. Quando se olha para as identificações das ações - Meninas que consertam, Meninas e as Bikes, Meninas que plantam e colhem insetos, Girls Rocky Camp -, percebe-se que há uma imagem, ainda que opaca, do reverso da princesa e não seria desprezível perguntar se estão associadas a comportamentos considerados masculinos, o que reforça o binarismo excludente. De um lado, portanto, repete-se o paradoxo da educação que sempre tem que admitir que qualquer proposta 
pedagogizável carrega um modelo ideal de ser humano, cuja subversão demanda um pensamento educativo sob o ponto de vista de sua negatividade. De outro lado, força a pergunta sobre uma possível associação entre o que se refere como empoderamento e uma adoção de características já, de antemão, associadas a uma representação, também problemática e reguladora do masculino.

Em outra iniciativa proposta como contraposição à pedagogia de princesas, relatada por Silva et al (2017), no texto "Marias vão com as outras": projeto de empoderamento feminino para meninas entre 10 a 14 anos, meninas foram levadas a refletirem sobre o que é ser mulher durante uma semana de debates, oficinas, contação de histórias e outras atividades lúdicas, manuais e criativas (SILVA, G., SILVA, I., MACHADO, 2017, p. 4). As autoras afirmam que, por motivos ideológicos, seu foco está na valorização de mulheres e meninas, o que as levaram a restringir a participação de meninas e de oficineiras que se identificavam como mulheres (SILVA, G., SILVA, I., MACHADO, 2017, p. 5). Não obstante, defendem que a "promoção da igualdade de gêneros se propague por muitos outros lugares" (SILVA, G., SILVA, I., MACHADO, 2017, p.. 8). Destacamos a persistência de um modelo feminino e a ideia de uma igualdade de gêneros que dispense o reconhecimento de diferenciações não enquadráveis dentro do binarismo homem-mulher.

$\mathrm{Na}$ perspectiva das provocações butlerianas, há muito que se pensar a esse respeito, na medida em que admitir qualquer representação sobre o que é ser mulher já significa submetê-la a uma regulação. "Se o gênero ou o sexo são fixos e livres, é função de um discurso que busca estabelecer certos limites à análise ou salvaguardar certos dogmas do humanismo como um pressuposto de qualquer análise do gênero" (BUTLER, 2003, p. 27). Ainda que a representação de mulher, insinuada no "Marias vão com as outras", subverta o modelo sugerido pelas Escolas de Princesas, corre o risco de estar, mais uma vez, enredada em ficções representacionais que facilitam estratégias de controle.

Pensar propostas educativas que levem em consideração o ultrapassamento desses discursos limitantes das possibilidades de ser é, de fato, tarefa complexa. No contexto das Escolas de Princesas, caberia um amplo trabalho de enfraquecimento das representações naturalizadas no âmbito familiar e uma abordagem crítica direta que motivasse a revisão imediata de algumas práticas, tais como a exclusividade de acesso justificada no gênero. Ademais, ações culturais que evidenciem as consequências de representações excludentes e baseadas no binômio Eu-Outro talvez abrissem novas 
perspectivas de análise para os que estão envolvidos com as justificativas da proposta.

\section{UM CURRÍCULO ALHEIO ÀS POTÊNCIAS DA DIVERSIDADE}

Antes de entrarmos nas questões relativas às representações da mulher, destacamos um caráter social a ser considerado. A realidade da Escola de Princesas, ao que parece, revela uma possível alienação quanto aos problemas sociais vigentes no País, na medida em que reproduz um contexto social, além de historicamente desconectado do mundo atual, indiferente às condições de exclusão social de um grande número de crianças. Julgamos relevante demarcar esse aspecto, dada a intersecção existente entre as questões de gênero e de classe, de forma que nos parece incoerente pensar os problemas derivados das representações sobre a mulher sem tocar no aspecto da diferença social.

Nossa ênfase, a partir daqui, é caracterizar mais detalhadamente os elementos do discurso da Pedagogia de Princesas, buscando os padrões do conceito de mulher nele impressos e a negação de possíveis derivações do modelo nele fundado. Fazemos essa leitura entendendo o currículo como uma estrutura discursiva associada a relações de poder, construída a partir de perspectivas de quem tem a garantia de exercício do poder em determinado contexto.

Começamos por citar um destaque feito por Knupp e Ripoll (2017) a respeito dos ensinamentos que uma das administradoras de uma das franquias da Escola de Princesas considera necessários para a formação da "princesa de verdade": o resgate de valores passados de avós para as mães e o abandono da "vulgaridade" atual. Aqui já detectamos um conteúdo moral conservacionista que conclama representações estanques para impedir formas variantes, de saída, acusadas de vulgares. Essas representações estanques, advindas de progenitoras, obviamente, podem guardar princípios perfeitamente androcêntricos. Smyl e Santos (2017, p. 3) nos apontam alguns deles: "valores que reforçam a formação das meninas para o casamento tradicional, como a valorização da aparência, além de práticas associadas ao espaço doméstico, de submissão corporal e de atitudes classificadas como femininas. É a própria idealizadora quem nos informa: "o passo mais importante na vida de uma mulher é sem dúvida o matrimônio. Nem mesmo a realização profissional supera as expectativas de um bom 
casamento" 4 .

No tópico do Programa Curricular intitulado "De Princesa à Rainha", a ênfase recai justamente sobre o matrimônio. As "educadoras" das Escolas de Princesas se propõem a restaurar valores e princípios morais do matrimônio. Certamente, não fazem isso na forma de uma catequese intragável para as meninas, mas utilizando-se das imagens de mulheres nas narrativas ficcionais, destinando-as ao papel das princesas que consagram seus projetos existenciais à conquista de seus príncipes. O tópico que especifica a forma como pretendem prepará-las para garantir essa conquista se chama “À espera do príncipe - como se guardar”, revelando outro aspecto regulador: a conquista do príncipe, o ápice do sonho de toda princesa, está condicionada ao “guardar-se"... É possível que estejamos incorrendo no risco de uma interpretação equivocada, uma vez que nos parece beirar ao inacreditável que esse termo esteja fazendo referência à contenção sexual da mulher que, novamente, depois de anos de debates e quebras de padrões referenciais, reconduz plenamente a experiência sexual aos interesses masculinos. Trata-se mesmo de uma apologia à virgindade condicionada à conquista do macho ideal? Ao que parece, sim. E já seria desgastante demais termos que nos debruçar criticamente sobre essa conservação se não encontrássemos o testemunho da grande incidência de mulheres latino-americanas que se submetem a cirurgias de reconstrução do hímen com o objetivo de conseguirem bons casamentos, conforme levantamento de Paternostro (1999), que nos faz pensar que algo, de fato, não se alcançou com os discursos feministas engendrados nas últimas décadas.

A idealizadora, Nathalia de Mesquita, nos informa o que entende por uma "Princesa de Verdade": não se trata de se vestir como princesa, mas de ser a "melhor versão de si mesma", adotando atributos de caráter e de comportamento de princesas em tudo que faz na vida. Esse fundamento, fortemente moralizante, é reforçado por ela, que diz desejar levar ao coração das meninas valores e princípios morais que sejam imutáveis e independentes de modismos. Acrescenta que acredita na construção de um caráter sólido e incorruptível.

Destaque-se que há, nas declarações da idealizadora, uma visão negativa em relação às consideráveis mudanças alcançadas pelos movimentos feministas, o que se evidencia pela acusação de modismos. Um dos discursos frequentemente utilizados contra o feminismo é justamente esse: o de pertencer à categoria de moda, como algo

\footnotetext{
${ }^{4}$ Disponível em www.escoladeprincesas.net.
} 
fútil e passageiro que, portanto, não merece atenção. Parece nítida uma crítica à emancipação feminina, à negação da reclusão ao espaço doméstico e da maternidade, à dedicação exclusiva ao mundo do trabalho. Lê-se importantes mudanças alcançadas pelos movimentos feministas. Outra questão evidenciada nas entrelinhas do currículo é a ênfase na palavra resgate. Tudo se passa como se houvesse, na história das mulheres, algum comportamento louvável que merecesse ser resgatado, quando, contrariamente, grande parte das pesquisas que têm como objeto tal história denunciam as opressões sofridas pelas mesmas ao longo do tempo.

Trata-se de um discurso moralizante e conservador que, ao se utilizar de uma imagem fortemente marcada por estratégias ficcionais, garante a adesão de mães e pais temerosos de perderem o controle sobre os processos de subjetivação de suas filhas. Isso, talvez, justifique o sucesso da proposta e seu rápido alastramento. O que mais poderia justificar que mães conduzam suas próprias filhas a esse mundo à parte, senãoum encantamento tardio por tais ficções, das quais também sua infância tenha sido povoada em virtude do alcance da cultura Disney, ou da necessidade de controle dos projetos existenciais de suas filhas, na tentativa de desviá-las de diferenciações consideradas inaceitáveis? Se a escola reduzisse seu marketing dizendo que ensinaria apenas as meninas a utilizarem apetrechos domésticos, como a máquina de lavar, seria improvável tamanha adesão, uma vez que, até para as mulheres para quem as teorias feministas sejam totalmente desconhecidas, já é inaceitável, ou ao menos questionável a liberação dos homens das tarefas domésticas. Se há uma força que atrai essas mães, certamente ela emana de estratégias discursivas mais sutis e assimiladoras, como os apelos morais, isso que é uma convicção para a idealizadora do projeto.

Quando o currículo de uma escola que proíbe a matrícula de meninos incorpora limpeza, organização, funcionamento de ambiente, educação financeira, corte e costura, culinária e lavanderia, fica implícito que as obrigações domésticas continuam sendo realmente obrigações das mulheres e que, portanto, tarefas domésticas merecem ser tratadas como conhecimentos escolares úteis apenas para meninas. Em entrevista cedida ao jornal Estadão, a idealizadora nega as acusações de estar resgatando costumes antigos, defendendo-se com o argumento de que reconhece e até pretende contribuir com as mulheres que saem para o mercado de trabalho:

Hoje os pais identificam a escola de princesas como um apoio à família, aquilo que se perdeu ao longo do tempo. A vovó ensinava para a mamãe, a mamãe nos ensinou e hoje a gente não tem mais esse tempo, 
porque a gente saiu para o mercado de trabalho, vieram vários fatores, então a gente não senta mais com a nossa filha e fala como ela deve arrumar a gaveta, como fazer o arroz" (ESTADÃO, 2016).

Torna-se necessário apontar que a ascensão social e o ingresso no mercado de trabalho por parte das mulheres não significa que a emancipação feminina e a verdadeira equidade entre os gêneros foram alcançadas, mas, sim, que a grande maioria das mulheres enfrentam jornadas duplas de trabalho. Tal declaração utiliza-se desse discurso de modernidade como um amenizador do discurso patriarcal, o qual reverbera a intenção de se confinar a mulher ao ambiente doméstico.

Outra aposta da idealizadora é se julgar conhecedora de algo como a essência feminina, uma vez que se propõe a conduzir as crianças ao seu resgate no interior de seus corações. Resta que tivesse ela mesma esclarecida de que nunca fora possível acessar tal essência e, portanto, sequer afirmá-la. De qualquer modo, ainda que tal pedagoga fosse agraciada com algum tipo de iluminação, caso ainda admitíssemos a ficção da iluminação total, seria preciso levá-la a constatar que busca essa essência não no coração das mulheres, mas em um acervo de constituições imaginárias permissivas das piores e mais excludentes representações sobre o que julga ser a mulher.

É indispensável apontar, ainda, para uma certa ingenuidade no testemunho da idealizadora, de que tal pedagogia tenha sido constituída a partir de um sonho, literalmente falando, e de que, "da data em que ocorreu até a sua abertura, foram oito meses de planejamento e registro de marcas e patentes, uma vez que não havia nada parecido no mundo!” (PAULINO, 2013.) Destaque-se o princípio fundante - um sonho literal - e o tempo de elaboração dos elementos teórico-metodológicos dos programas propostos - perfeitamente incompatíveis com os requisitos para a solidez de qualquer pedagogia. Não obstante, o conjunto desses elementos é referido pela idealizadora como Pedagogia das Princesas que, certamente, permanece desconhecida e, quiçá, rejeitável para muitas sociedades no mundo.

\section{REESCRITURAS E RESISTÊNCIA}

Faremos, como exercício final para pensarmos o universo povoado pelas representações expressas no currículo das Escolas de Princesas, uma compilação de análises de iniciativas de reescrita de narrativas em que as princesas sejam centrais e a citação de um texto onde se argumenta a favor da positivação dos efeitos de tais narrativas ficcionais. Inicialmente, destacamos que pressupomos, assim como Ramalho 
(2001), que os signos como fadas, bruxas, príncipes, princesas, reis e rainhas estão presentes nas narrativas como "metáforas do próprio homem, sujeito às ordens morais e aos códigos de comportamento social" (RAMALHO, 2001, p. 47). Esse pressuposto nos permite apontar a não neutralidade do uso dessas imagens.

Maria Cristina Martins (2006, p. 158), no texto Histórias que nossas Mães não nos Contaram: o revisionismo feminista dos contos de fadas, comenta as iniciativas de escritoras contemporâneas de confrontar imagens cristalizadas pelo discurso patriarcal na reescritura de contos de fada, transgredindo ou subvertendo noções do feminino reforçadas nessas conhecidas histórias de nossa infância. Nessas reescrituras, "apesar do reconhecimento das fontes ser não somente possível como também desejável, é propiciado um distanciamento crítico em relação aos textos originais, expondo, por exemplo, o caráter sexista e misógino de muitas dessas histórias. (MARTINS, 2006, p. 159).

Entre as iniciativas revisionistas dos contos de fadas, Martins (2006, p. 159) destaca as de Angela Carter, A.S.Byatt e Margaret Atwood. A título de exemplos, destacamos: em The Robber Bride (1993), Atwood relê o conto dos Grimm, O noivo ladrão, invertendo o gênero do protagonista (Zenia), "de modo a ferir irremediavelmente a dicotomia tradicional de papéis sexuais das histórias infantis"; em The Djinn in the Nightingale's Eye, releitura da estória do gênio da lâmpada, A. S. Byatt inverte os papéis tradicionais do conto, fazendo com que a protagonista Gillian concedaao gênio a realização de seu último desejo, livrando-o de sua escravidão ao desejo dos outros.

Gomes (2007, p. 163) comenta as narrativas ficcionais feitas por Colassanti, em que se apodera do formato dos contos de fada para veicular "símbolos que metaforizam imagens e representações de mulheres". Nos textos, aparecem tanto imagens "parodicamente construídas sob a égide da ideologia e do poder dominantes, ou seja, numa perspectiva a partir do olhar masculino sobre o corpo feminino", quanto imagens "transgressoras dos padrões de conduta permitidos socialmente". O autor considera, ainda, que a escritora vai além quando "se liberta dos estereótipos e apresenta personagens femininas fortes e atuantes, remete para as mudanças, para as lutas, para as dificuldades superadas" (GOMES, 2007, 163).

Há que se considerar que, da mesma forma que as propostas de desaprincesamento, essas reescritas guardam o risco de apontarem para novos sujeitos femininos, novos modelos sobre o que é ser mulher, o que não lhes tira a importância de um papel de resistência aos discursos androcêntricos. A positivação dessas 
iniciativas, no entanto, não é espaço consensual. Há apontamentos de críticas no que se refere à mudança de papéis ou a gênero nas narrativas, conservando um padrão binário problemático ou travestindo as mulheres de características masculinas, no lugar de colocar em suspensão as caracterizações reforçadoras de conceitos estanques sobre mulheres e homens. Quanto a essas críticas, consideramos que precisam ser consideradas e amplamente discutidas. No entanto, destacamos uma vertente delas que acaba por reconduzir a estereótipos e, portanto, precisa ser olhada com maior cuidado.

No texto Vozes femininas nos contos de fadas: a Experiência da fala falante, Clarice Caldin (2006) encaminha um argumento de positivação dos contos de fadas, defendendo o poder de voz de personagens femininas e discordando das críticas feministas apontadas para tais narrativas. Nesse encaminhamento, volta-se para as escritas contemporâneas que subvertem as imagens femininas nos contos. Atentemos para alguns de seus argumentos:

$\mathrm{Na}$ tentativa de apresentar uma mulher atuante na trama, as escritoras contemporâneas esboçam histórias de mulheres bem sucedidas profissionalmente, mas que, em matéria de vida sentimental, são um fracasso. É como se a fala falante no exercício da profissão impedisse o coração de sentir. É como se recebessem uma punição pelo privilégio da voz. Como paliativo, o sexo promíscuo que satisfaz por instantes, mas deixa lacunas ao longo do dia (CALDIN, 2006, p. 289).

Parece evidente, no argumento de Caldin, um discurso conservador subsumido em representações da mulher já denunciadas como comprometidas com políticas regulatórias. Faltou ao argumento uma riqueza maior de detalhes para que pudéssemos ter claramente e, não sutilmente, exposto um princípio de contenção. Por exemplo, seria necessário que a autora nos esclarecesse o que entende por fracasso em matéria de vida sentimental. Trata-se do que consideraria uma incapacidade de adequação à vida compartilhada com outro vivente, ou com outras manifestações existenciais que ela chamaria, de antemão, masculinas? Ou, de outro lado, o fracasso sentimental diz respeito mesmo à não organização da vida prática em formas inspiradas no matrimônio? Ou, ainda, trata-se de uma repetição da associação machista entre o feminino e um suposto desequilíbrio emocional que caracterizaria o comportamento da mulher? Outra questão que necessitaria esclarecimento: está, de fato, a partir de seu próprio juízo moral, caracterizando, na mesma medida em que condena, o sexo promíscuo como algo não permissível ou adequado às mulheres? Está, além disso, cristalizando a ideia de que a permissividade sexual é causa de um vazio existencial? 
Não faltou prever que tal vazio possa ser o incontornável de qualquer condição existencial, motivado muito mais pelas imagens de super-humanidade que os humanos sapientes conferem a si mesmos e que se desnaturalizam facilmente diante da constatação de sua finitude e de seus mínimos? Ao que parece, a velha redução moralizante foi, aqui também, reproduzida.

A autora segue apresentando alguns exemplos de versões originais de contos, como Cinderela e A bela adormecida, em que podem ser positivadas as imagens femininas. Descreve a versão camponesa de Cinderela, em que a personagem, submetida à fome e ao excesso de trabalho, encontra uma árvore frutífera cujos ramos só são acessáveis por ela e que, com a possibilidade de colher e oferecer seus frutos, conquista um guloso príncipe e um bom casamento. A autora considera: "a moça, na verdade, não precisa do príncipe para sua sobrevivência e nem está à sua espera. É por acaso que aparece um príncipe e não há romance: o interesse dele está concentrado nas frutas". Consideremos, no entanto: o príncipe e o casamento configuram o desfecho de toda uma história!

Quanto ao conto A Bela Adormecida, a autora destaca que, na história original, o final não é o beijo do príncipe acordando a bela, mas a princesa acordando com a chegada do príncipe, não havendo beijo, mas uma longa conversa. Ora, isso não conduz, necessariamente, à narrativa para outro lugar da mulher que não o de uma existência atravessada pela imagem de um outro que, nesse caso, nem destoa da representação do príncipe na vida da princesa. Da mesma forma que o exemplo anterior, o príncipe está lá, ainda que variem as formas de encontrá-lo, conquistá-lo e, assim, conduzir a mulher à existência de um homem. Ainda mais, não de qualquer homem, mas de um homem enquadrado em uma representação de homem ideal. É um príncipe, não um marginal, nem um ladrão, nem um impostor. Ele prefere a longa conversa ao beijo... Não é um animal sem modos, nem um amante de sexo, mas um cordial exemplar masculino da espécie Homo sapiens, que precisa ser agarrado por uma fêmea, que a ele quer se submeter, garantindo a consagração da própria existência a seus desejos ou a quem ela quer submeter, colocando-o a serviço de seus caprichos de princesa...

O problema se agrava quando assistimos ao estímulo de crianças a conservarem os mesmos equívocos admitidos por gerações anteriores. Se quisermos um exemplo prático de como isso se reafirma no universo infantil, podemos atentar para as informações trazidas por Constantina Xavier Fl a respeito de seu estudo sobre 
concepções de gênero da princesa Barbie, a partir de filmes de animação e das falas das crianças. As narrativas das crianças repetem características comportamentais das princesas, descritas como felizes, vaidosas, bonitas, amantes dos animais e esperançosas de encontrar um príncipe encantado. Para meninos, elas são "sorridentes e gostam de boneca", indicando um lugar a que o discurso androcêntrico sempre destinou à mulher. Para meninas, elas têm "asseio, doçura, discrição, delicadeza, inteligência, fofura, meiguice, amabilidade", além do gosto pela cozinha e pelo uso da cor rosa (XAVIER Fl, 2016, p.22). A autora se aproxima das mesmas considerações que apresentamos aqui, indicando que esses aprendizados sociais, evidenciados nas falas das crianças, estão impregnados pela visão binária de ser masculino/feminino, quase sempre indicando uma forma única de ser homem/mulher (XAVIER Fl, 2016, p.24).

Adicionalmente, a autora contribui com a análise sobre a escola de princesas, ambiente onde se passam as tramas do filme Barbie. Segundo a autora, no filme, bolsas de estudos são sorteadas para ingresso de plebeias na escola, dando-lhes a oportunidade de descobrirem em si o potencial da princesa, atuando, posteriormente, como dama real. O currículo da escola visava "promover seu aprendizado e despertar nela a princesa em potencial, com aulas de etiqueta à mesa, de modos de se vestir, de dançar, entre outros conteúdos de aprendizado de uma suposta feminilidade ideal" (XAVIER Fl, 2016, p.25). O que não imaginávamos era a possibilidade imediata dessa ambiência e desse currículo se materializarem, ipsis litteris, nas redomas protegidas desse nosso mundo fático, repleto de complexidades e diferenciações, tão tardia quando descontextualizada.

Em resposta a esse cenário, Constantina destaca a experiência de invenção do filme A Princesa Pantaneira (2012), que conta a história de Camuela, "Princesa Pantaneira", que um dia ouviu o grito de um príncipe preso em uma torre rodeada de bichos enfeitiçados, a quem se dispõe a salvar. À princesa da narrativa, as crianças associaram os atributos: "morena, corajosa, alegre, monta e doma cavalo bravo, salva o príncipe, é decidida, às vezes tem dúvidas, sente medo e pede colo, mas logo volta a sonhar, a imaginar e a viver muitas aventuras" (XAVIER Fl, 2016, p.32). Ainda uma princesa... Ainda um príncipe... Dispostos em condições inversas.

\section{CONSIDERAÇÃO FINAL}

Tecemos uma síntese a partir do desdobramento dessa nossa última reflexão, referente às reverberações de discursos que apostam no esgotamento do que é ser 
humano, ser mulher, ser homem em padrões unívocos, evidenciadas nas Escolas de Princesas.

No fechamento do seu texto, Constantina afirma: "descontruir as figuras da princesa, questionar e produzir outras formas de ser princesa, de ser príncipe, de ser criança, de ser adulto, de ser gente... Eis um delicioso desafio! (XAVIER Fl, 2016, p.35). Talvez, um dia, estejamos desprendidos de forças assimiladoras das ficções constituintes a ponto de reescrever sua conclusiva: "descobrir as figuras, questioná-las e produzir uma contínua suspensão de todas as formas... Eis um incontornável desafio!”.

\section{REFERÊNCIAS}

BEAUVOIR, Simone. O segundo sexo. Fatos e Mitos. $4^{\mathrm{a}}$ ed. Difusão Européia do Livro, Paris: Gallimard, 1970.

BUTLER, Judith P. Problemas de gênero: feminismo e subversão da identidade. Rio de Janeiro: Civilização Brasileira, 2003.

CALDIN, Clarice F. Vozes femininas nos contos de fadas: a experiência da fala falante. Revista ACB: Biblioteconomia em Santa Catarina, Florianópolis, v.11, n.2, p. 283-296, ago./dez., 2006.

FREITAS, Hyndara. Escola de Princesas ensina etiqueta, culinária e organização de casa a meninas de 4 anos. Estadão, São Paulo, 12 de out. 2016. Disponível em: https://emais.estadao.com.br/noticias/comportamento,escola-de-princesas-ensinaetiqueta-culinaria-e-organizacao-de-casa-a-meninas-de-4-a-15-anos, 10000081544. Acesso em: 13 jul. 2018.

GOMES, Anderson. "A quem interessar possa": entrevista com Marina Colasanti. Uniletras, Paraná, v. 29, n. 1, p. 162-169, dez. 2007.

HARARI, Yuval N. Sapiens: uma breve história da humanidade. Trad. Janaína Marcoantonio. Editora J\&PM, 2014.

KNUPP, Antonio J. F.; RIPOLL, Daniela. Lições dos concursos infantis de beleza e da escola de princesas. In: Seminário Brasileiro de Estudos Culturais e Educação, 7., 2017, Canoas. Anais [...]. Canoas, 2017.

MARTINS, Maria Cristina. Histórias que nossas Mães não nos Contaram: o revisionismo feminista dos contos de fadas. Em Tese, Belo Horizonte, v. 10, p. 157163, dez. 2006.

MESQUITA, Nathalia. Nathália de Mesquita: todas as mulheres são princesas ou rainhas, mas algumas esquecem. Uai, Minas Gerais, 30, ago. 2013. Disponível em: https://www.uai.com.br/app/noticia/saude/2013/08/30/noticias-saude, 193966/nathaliade-mesquita-todas-as-mulheres-sao-princesas-ou-rainhas-mas.shtml. Acesso em: 13 jul. 
2018.

RAMALHO, Christina. Mulheres, princesas e fadas: a hora da desconstrução. Revista Gênero. v. 1, n. 2. p. 47-56, 2001.

SILVA, Gabriela; SILVA, Izabele C.; MACHADO, Rafaella. Marias vão com as outras: projeto de empoderamento feminino para meninas entre 10 a 14 anos. In: Seminário Internacional Fazendo Gênero, 13., 2017. Anais [...]. Florianópolis, 2017.

SMYL, Elaine B.O.; SANTOS, Marinês R. Cursos de "desprincesamento": estratégias feministas de resistência. In: Seminário Internacional Fazendo Gênero, 13., 2017. Anais [...]. Florianópolis, 2017.

XAVIER Fl., Constantina. Gênero e resistências em filmes de animação. Pro-Posições, Campinas, v. 27, n. 1 (79), pp. 19-36, jan./abr. 2016 